\title{
NFT CONTROLLED - ENVIRONMENT FACTORS AFFECTING PRODUCTION OF GREEN FODDER
}

\author{
M. A. MOSALLAM ${ }^{(1)}$, \\ M. E. SHETAWY ${ }^{(2)}$, \\ R. R. EL-BESSOUMY ${ }^{(3)}$ and T. ABDEL - FATTAH ${ }^{(4)}$
}

\begin{abstract}
A Nutrient-Film Technique "NFT" and A semi-Environmental control chamber were used to detect the effect of slope and environmental parameters affecting the NFT. The environmental parameters are: concentration of the nutrient solution "NS" , lighting type and light exposure and air change per hour. Four slopes were tested; from: 5 to 25\%. Three concentrations were tested: from: 0.5 to $1.5 \%$ in addition to tap water as control. Three types of lighting were tested: light-emitting diodes $\left(L E D_{S}\right)$, fluorescent lamps and compact fluorescent lamps $\left(C F L_{S}\right)$ in addition a natural light as control. Four lighting times were tested: from: 6 to 24 h/day. Four airing rates were tested: from 30 to 60 times per hour. The optimal parameters for transplanting fodder are : the slope of NS channel of 5\%, the feed pump discharge of $4.66 \mathrm{~L} / \mathrm{min}$ under cultivating density of $1.6 \mathrm{~kg} / \mathrm{m}^{2}$ and the discharge corresponds to an empirical depth and an empirical speed of the NS(measured from a previous study of NFT unit without cultivation, Mosallam et al.,2015) this depth and this speed are $3 \mathrm{~mm} 0.1 \mathrm{~m} / \mathrm{s}$, respectively, concentrations of the nutrient solution $1 \%$, lighting type :light-emitting diodes $\left(L E D_{S}\right)$, lighting exposure: $12 \mathrm{~h} /$ day and air change rate of 40 times $h$.
\end{abstract}

Keywords: nutrient-film technique, semi- environmental control chamber, LED light source, nutrient solution, air change rate.

\section{INTRODUCTION}

$\checkmark$ gypt, like other developing countries of the arid and semi- arid regions, faces four major problems, namely: high rate of population increase; limited natural sources of good quality water; existence of salt-affected land ;shortage of food and feed. Therefore, studies should be oriented towards solving these problems, Ashour et al. 1997.

(1) Prof., (2) Assoc - prof., (3) Lec.;(4) Teachg. Assist. All in the Fac. Ag. Eng., AL- Azhar univ., Cairo. 
Nutrient film technique (NFT) is the system which makes efficient use of water, fertilizers, non-arable land for optimized productivity, Resh 1991 and Al-Karaki et al,. 2012.

This research aims to study design and environmental parameters affecting the NFT to maximize green fodder production under this system.

\section{REVIEW OF LITERATURE}

Cooper 1996, reported that: the design key requirements in achieving NFT unit are : suitable slope of the channel of the nutrient solution, the inlet flow rate must not be so rapid that a considerable depth of water flows down the gradient, the width of the channels in which the roots are confined must be adequate to avoid any damming up of the nutrient by the root mat and ensure that the depth of the nutrient solution is only a few millimeter at the most. Spensley et al., 1978, Lynette 1999 and Carly 2011 found that slope of the channel of the nutrient solution must not be less than $1 \%$. Jenner et al.,(1980) mentioned that: the discharge of the feeding pump should not be less than $2 \mathrm{~L} / \mathrm{min}$ and this discharge depends on the size of the plant and intensity of cultivation. Graves (1983) reported that the flow of nutrient solution into each channel should be 2-3 liters per minute. Maher (1977) mentioned that low solution flow rates $(2 \mathrm{~L} / \mathrm{min})$ also can result in dramatically falling oxygen concentration in NFT system. Graves and Hurd 1983 mentioned that depth of the nutrient solution is $1-3 \mathrm{~mm}$.

Ikeda et al., 2011 in recent years, with the development of agricultural science, system science and computer technology, the study on crop growth environment system has gradually become a new area of research. Temperature, humidity, light, carbon dioxide (CO2) concentration, air movement and nutrient are the main environmental regulatory factors affecting crop growth. The crop growth environment simulation system is an automated or semi-automated control system in greenhouse or growth chamber by simulating the natural environment of crop growth with environment control technologies, Liguo et al,. 2014. 
Liguo et al., 2014 also added that nutrition is one of the primary indispensable factors in crop growth. Different crops and different stages of crop life cycle have different needs for nutrients. Massantini and Magnani 1980 and El-Deeba et al., 2009 reported a positive response to added nutrient solution, which is temperature related. Light is one of the most important environmental factors which acts on plants as one source of energy. Jane et al., 2011found that the plant responds to light quantity and quality and duration. Bourget 2008 and Morrow et al., 2005 Compared to those conventional light sources, gallium-aluminum and light-emitting diode (LED).The light-emitting diode has several unique advantages, including the ability to control the spectral composition, a small mass and volume, long operating lifetimes, relatively cool emitting surfaces, minimum heating. El-Deeba et al., 2009 fond that lighting time $12-16 \mathrm{~h} /$ day is optimal for production of barley green fodder. Ventilation in agricultural facilities helps regulate temperature , humidity and exhaust of harmful gases, Stout et al., 1984. Aldrich et al., 1994 reported that ventilation systems in agricultural buildings can be classified into three classes: negative pressure, positive pressure and neutral pressure. Gordon ,2008 recommended an ideal environment of at least 30 air changes per hour.

\section{MATERRIALS AND METHODS}

This study aims to investigate the slope and environmental parameters affecting the NFT. These parameters are:

The environmental parameters : concentration of the nutrient solution , lighting type and light exposure and air change per hour.

To study the previously mentioned parameters , an "NFT" and a semienvironmental control chamber were constructed. Fodder seeds and nutrient solution were used.

The "NFT" : Fig.(1) shows the unit. The unit consists of a channel for the nutrient solution, made from acrylic of thickness $4 \mathrm{~mm}$ and dimensions $67 \times 28 \times 4 \mathrm{~cm}$. At the head of the channel, a hole for entrance of the nutrient solution was made. The hole diameter is $15 \mathrm{~mm}$. At the end of channel, 7 holes for drainage the nutrient solution were made. Each of hole diameter was $7 \mathrm{~mm}$ and these 7 was distributed through the width of the channel. 


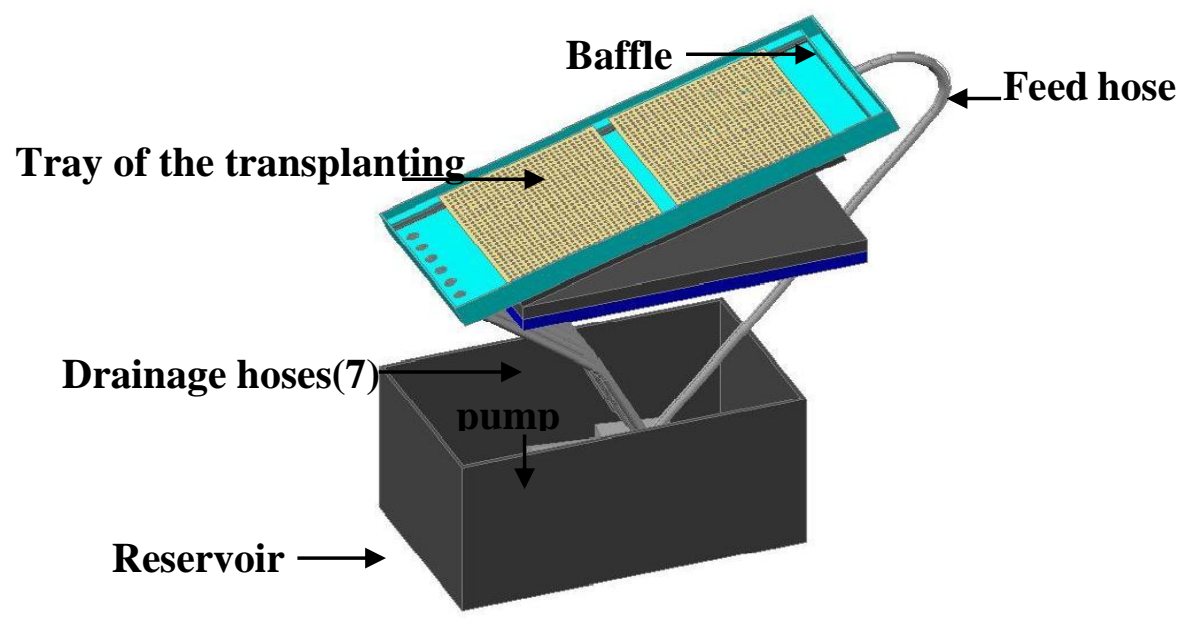

Fig.(1):The (NFT) unit.

Experimented transplanted seeds were cultivated over tray. Each tray was of dimensions of $24 \times 26 \mathrm{~cm}$ and each tray was made from acrylic of thickness $4 \mathrm{~mm}$. The tray had pierced openings, to allow the roots to contact with the nutrient solution. The opening diameter was $3 \mathrm{~mm}$. A reservoir of the nutrient solution capacity is of 20 liter was used. Feeding pump (RS-3001) was used to force the nutrient solution into the channel of a closed recirculating system.

The semi- environmental control chamber: plate (2) shows the semienvironmental control chamber. Its dimensions were: $100 \times 150 \times 150 \mathrm{~cm}$. The chamber was constructed from wood of thickness $1.8 \mathrm{~cm}$. The chamber was divided into four compartments, each of dimensions of $37.5 \times 100 \times 100 \mathrm{~cm}$. Each compartment had a separate door for allowing a separate experiment from other compartments. To allow following - up the experiments without opening the compartment door, a transparent sheet of the poly- acrylic of thickness $1.5 \mathrm{~mm}$ was installed at the door of the compartment. On the rear side of the compartment, an exhaust fan was installed. For allowing an appropriate ventilation rate, circular openings (each $1.8 \mathrm{~cm}$ diameter) were made on the transparent poly- acrylic sheet. A shelf was installed inside the compartment, the 
shelf slope was determined according to slope experiments. The inner side of the roof has been designed to allow installing different lighting systems. The inside walls of the compartment were painted white.

Cultivated seeds: Two types of green fodder seeds were used in this study: barley (Giza جيزة 168) شندويلى ). The season of cultivation determined the type of fodder.

Nutrient solution(NS):The NS solution developed by El-Behairy 1994 was used. It nutrient solution consists of:

\begin{tabular}{|c|l|l|l|l|l|l|l|l|l|l|l|c|}
\hline Nutrient & Mo & $\mathbf{Z n}$ & $\mathbf{C u}$ & $\mathbf{B}$ & $\mathbf{M n}$ & $\mathbf{F e}$ & $\mathbf{S}$ & $\mathbf{M g}$ & $\mathbf{C a}$ & $\mathbf{K}$ & $\mathbf{P}$ & $\mathbf{N}$ \\
\hline $\begin{array}{c}\text { Amount } \\
\text { ppm }\end{array}$ & 0.1 & 0.1 & 0.1 & 0.3 & 1 & 5 & 221 & 50 & 160.2 & 300 & 35 & 295.6 \\
\hline
\end{tabular}

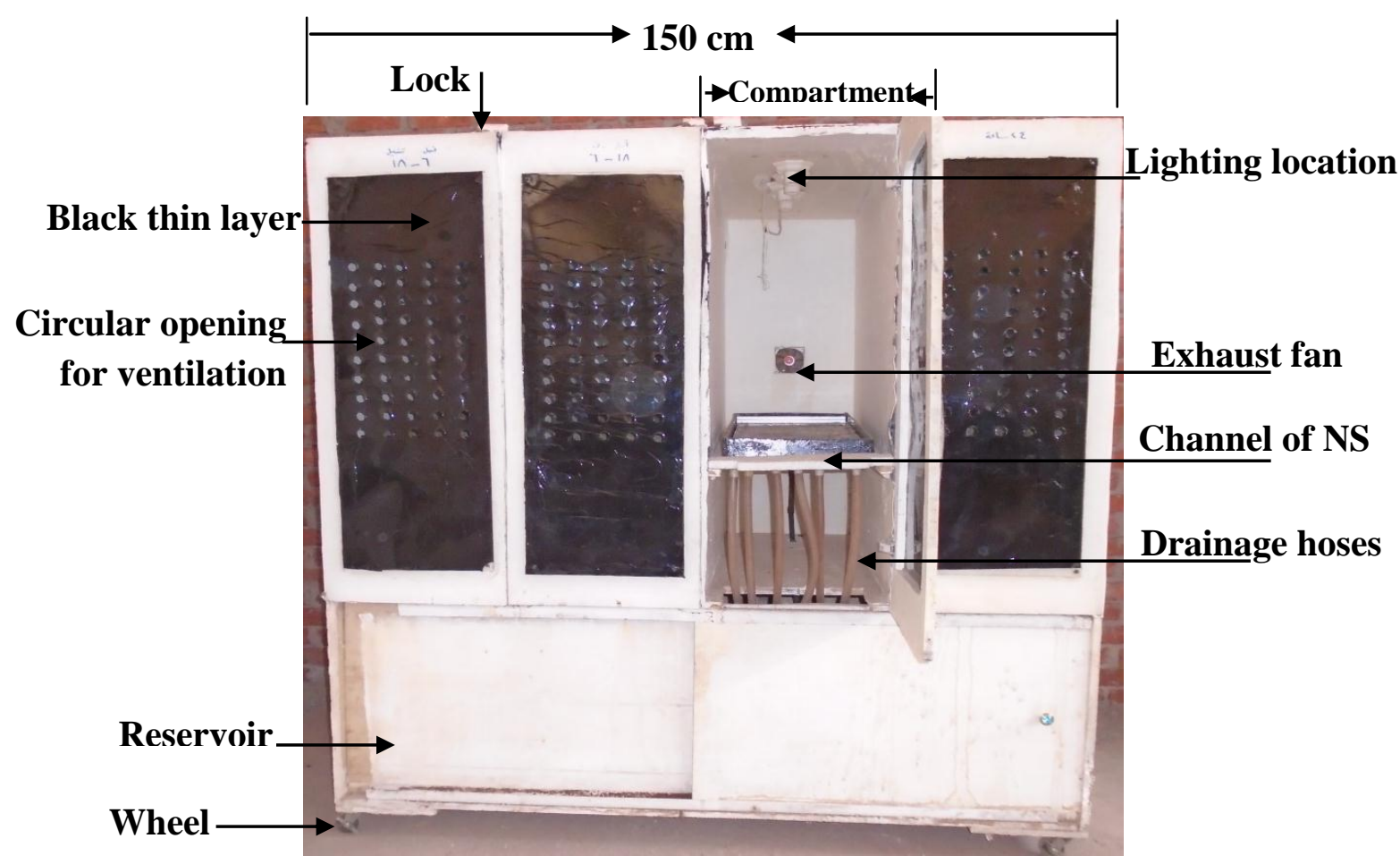

The depth of chamber is $100 \mathrm{~cm}$

Plate (2): The semi - environmental control chamber.

To investigate the effect of channel slope on growth of pearl milt, four slopes were tested. These slopes were: $5,10,15,20$ and $25 \%$. under feed pump discharge of $4.6 \mathrm{~L} / \mathrm{min}$. The optimal slope under corresponding 
discharge obtained through the experiment will be related to each depth and the NS before transplanting according to Mosallam et al., 2015.

To investigate the effect of concentration of the NS on growth of barley, three concentrations were tested $: 0.5,1,1.5 \%$ in addition to tap water as a control.

To investigate the effect of lighting type on growth of barley, three types of lighting were tested. These types were: light- emitting diodes $\left(\mathrm{LED}_{\mathrm{S}}\right)$, fluorescent lamps and compact fluorescent lamps $\left(\mathrm{CFL}_{S}\right)$ in addition to natural light as control.

To investigate the effect of light time exposure on growth of barley, four lighting durations were tested: These times were: $6,12,18$ and $24 \mathrm{~h} /$ day. To investigate the effect of air change rate on growth of barley, four rates were tested: $30,40,50$ and 60 times per hour.

The slope experiments were carried out on pearl millet, then the environmental experiments were carried out on barley. This was according to the ambient temperature.

Number of replicates of each experiment was two.

\section{RESULTS AND DISCUSSION}

1- Effect of the slope of the channel of the nutrient solution on the growth of pearl millet:

Figure (4) shows the relationship between time of pearl - millet growth and the fresh mass under the four tested slopes(5,10.20 and 25\%).

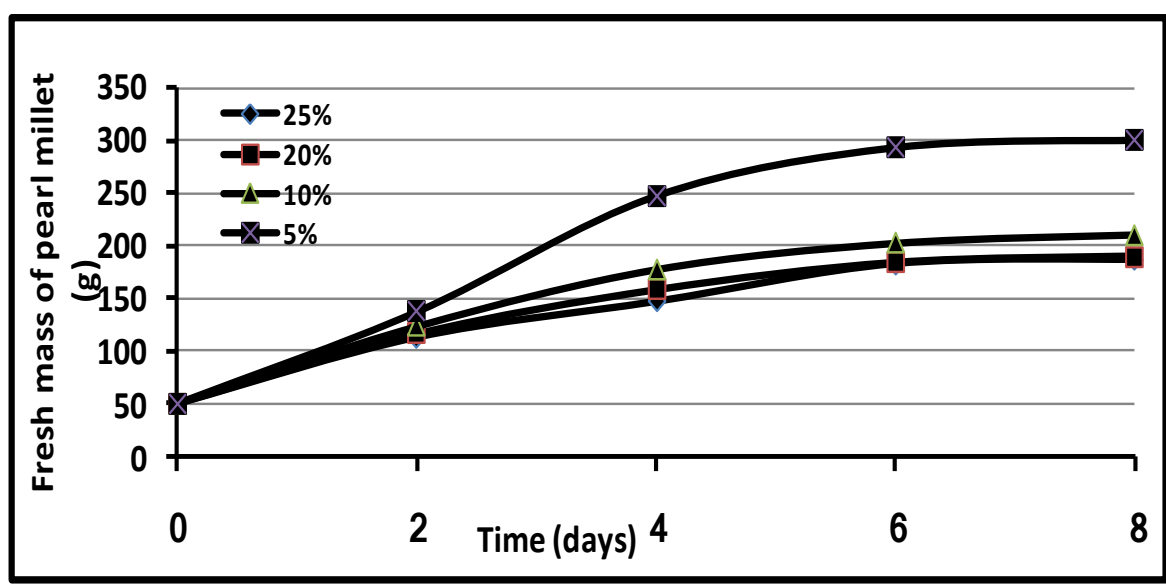

Fig.(4): Pearl millet growth and fresh mass under four slopes of the NS channel. 
Generally, for the four slopes, there was a gradual increase in fresh mass with time of growth. The curves that represent the relation between production and slopes 10,20 and 25\% approache each other. This means that the three previously mentioned slopes are simillar in their effect of the production. A significant increase in the production of pearl millet occurred at 5\% slope. This suggests that still less slope can be used,5\% slope with $4.6 \mathrm{~L} / \mathrm{min}$ feed pump discharge , 3mm empirical ( revise Mosallam et al., 2015) depth and $0.1 \mathrm{~m} / \mathrm{s}$ empirical speed of the NS can be found from the graphs, without cultivation as shown in figs. (2)and (3), in accordance to; Mosallam et al,. 2015. Each empirical depth and empirical speed of the NS may guide of the depth and the speed of the NS when transplanting.

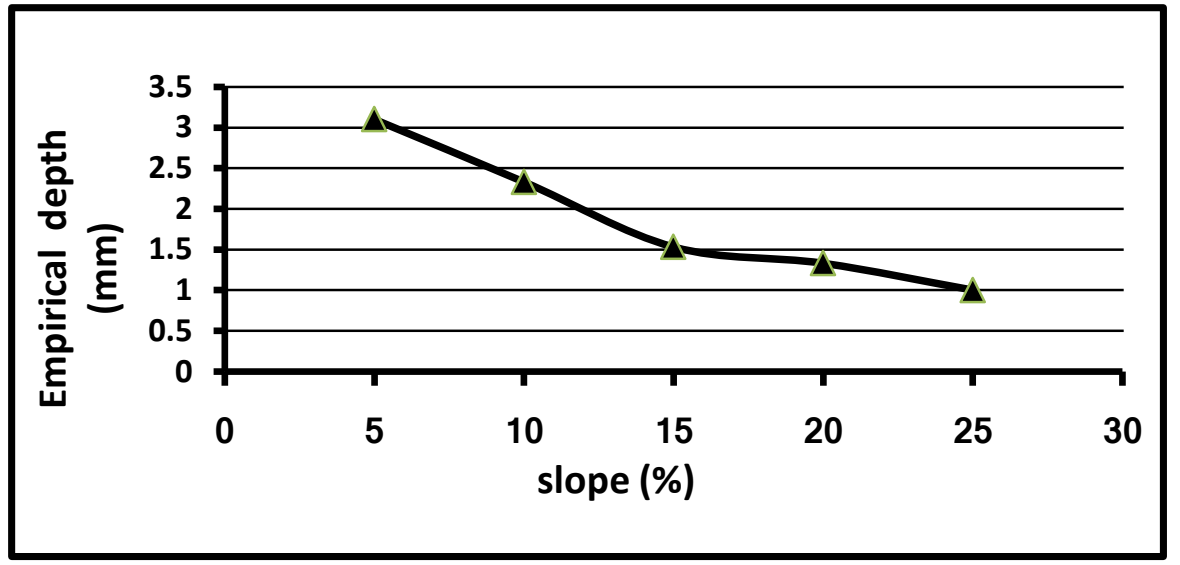

Fig. (2): Slope of the NS channel and the empirical depth under $4.66 \mathrm{~L} / \mathrm{min}$ feed - pump discharge,( Mosallam et al., 2015)

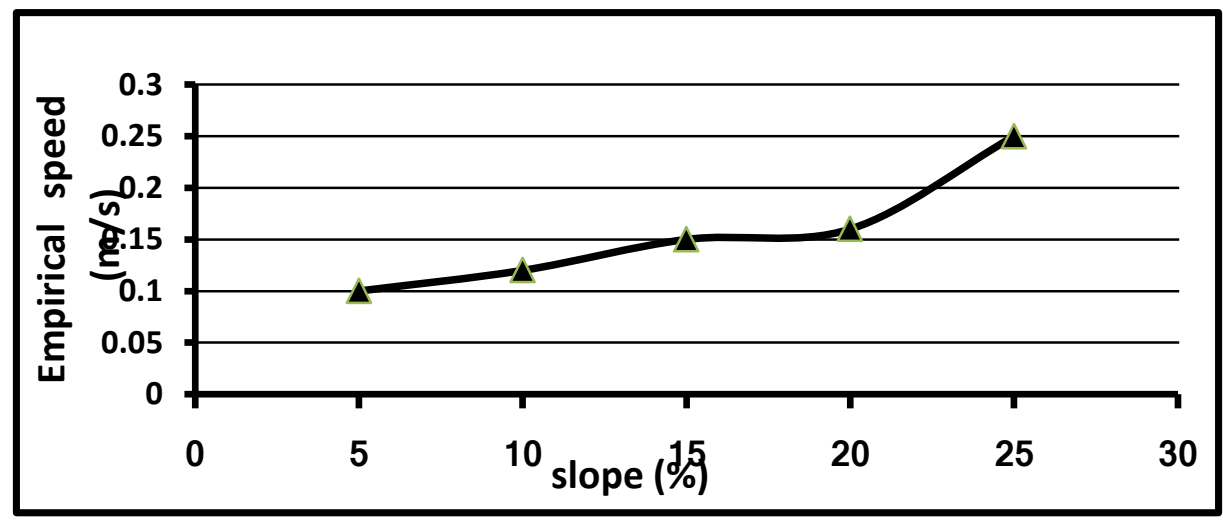

Fig. (3): Slope of the NS channel and the empirical speed under $4.66 \mathrm{~L} / \mathrm{min}$ feed - pump discharge,(Mosallam et al., 2015). 
2- The relation between the price of the NS and the production of barley:

Figure (5) shows the relationships between the price of the nutrient solution and the production of barley under the three concentrations of the nutrient solution $(0.5,1,1.5 \%)$ in addition to tap water control.

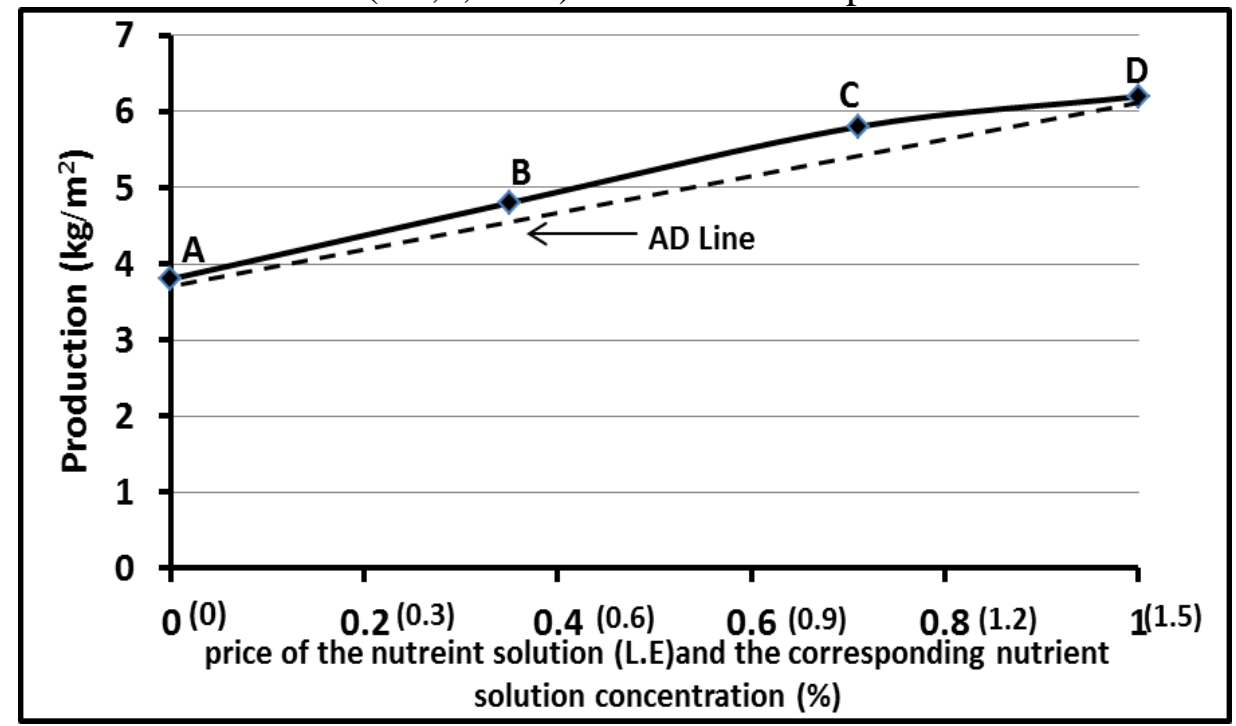

Fig.(5):The relationship between the price of the nutrient solution and the production of barley.

The points $(A, B, C)$ belong to a definite straight line while the point (D) does not belongs to this line. The slope (money rate) of the $\mathrm{ABC}$ line (the continuous line) is calculated to be $2 \mathrm{Kg} / \mathrm{m}^{2}$.L.E and this slope is found to be greater than the slope of the AD line (the dashed line) which is 1.6 $\mathrm{Kg} / \mathrm{m}^{2}$.L.E .This means that the production due to addition of one unit of money price of the nutrient solution is better in the case of $\mathrm{ABC}$ line ( nutrient solution concentration $0.5-1 \%$ ) than that of $\mathrm{AD}$ line than. The previous discussion indicates that, from point of view of price of NS, concentration range of $0.5-1 \%$ corresponding to price of the used quantities of NS (0.33-0.66 L.E) is more economic than concentration of $1.5 \%$.

3- Effect of the lighting type on the growth of barley:

Figure (6) shows the relationships between time of the barley growth and fresh mass under four tested lighting types: natural light, light emitting diode(LED) 10W, fluorescent lamps 20W, and compact fluorescent lamps(CFL) 30W. 


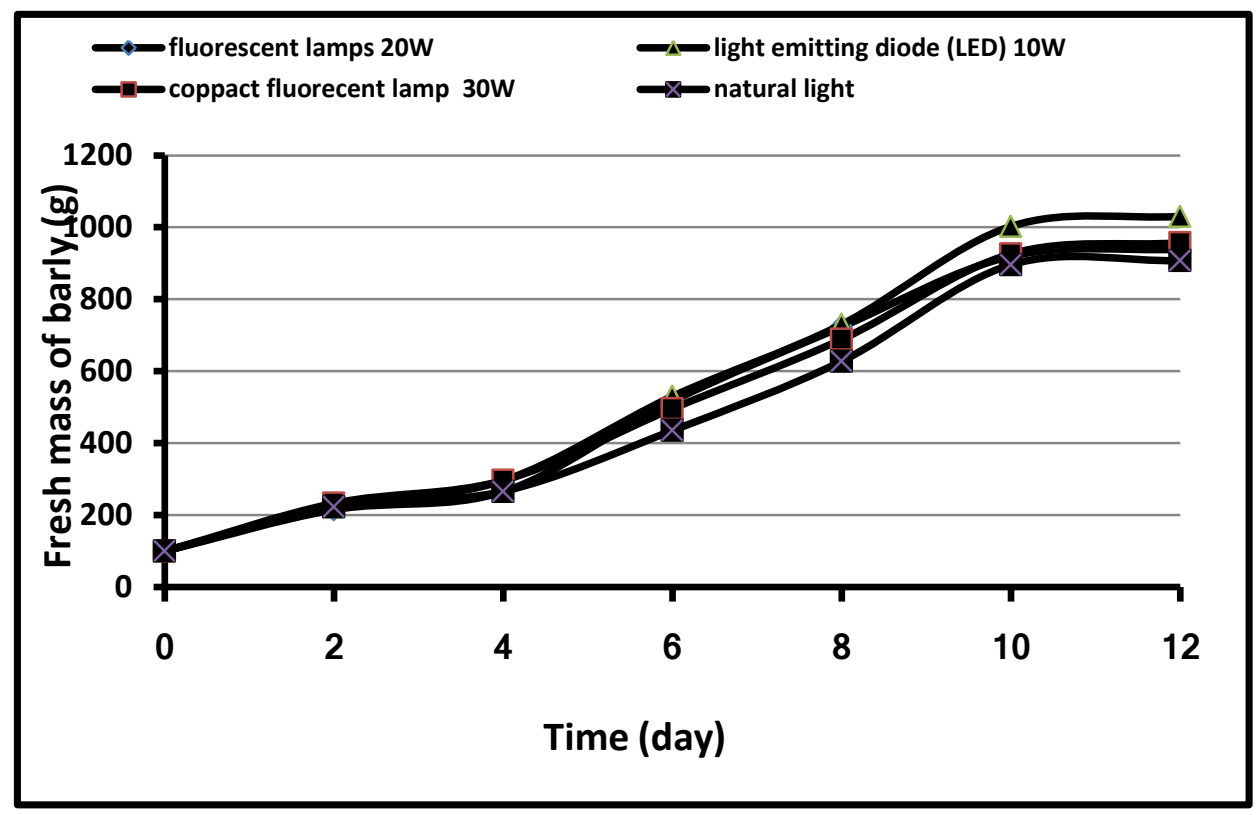

Fig.(6): Time of the barley growth and the fresh mass.

Under the four lighting types, the relation between time of barley growth and fresh mass is increasing from 1:10 day. There is a slight difference between the results for the four lighting types. however, increase seams to diminish after ten days.

To reduce the consumption of energy for growing fodder, the effect of the lighting type on growth of the pearly was studied. Figure (7) shows the relationships between the lighting and the quantity of electricity consumed $(\mathrm{kW} . \mathrm{h})$ through the experiment period. The lowest electricity consumption is obtained under (LED).

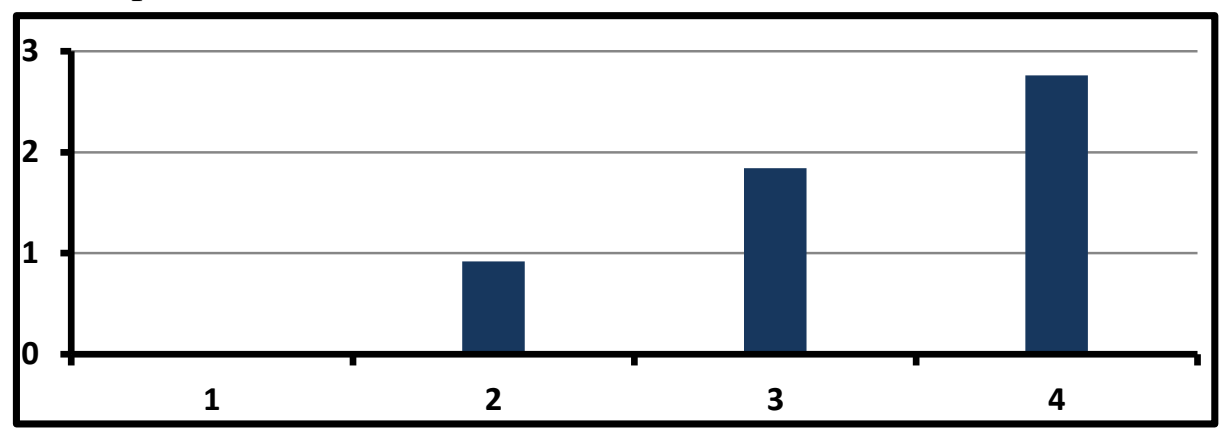

Fig.(7):The relationship between the light types: (1) natural light,(2) light emitting diode (LED), (3) fluorescent lamps, (4) compact fluorescent lamps and electricity consumed $(\mathrm{kW} . \mathrm{h})$. 
Effect of lighting time on growth of barley:

Figure (8) shows the relationships between time of the barley growth and fresh weight under the four lighting times tested: $(6,12,18$ and $24 \mathrm{~h} /$ day).

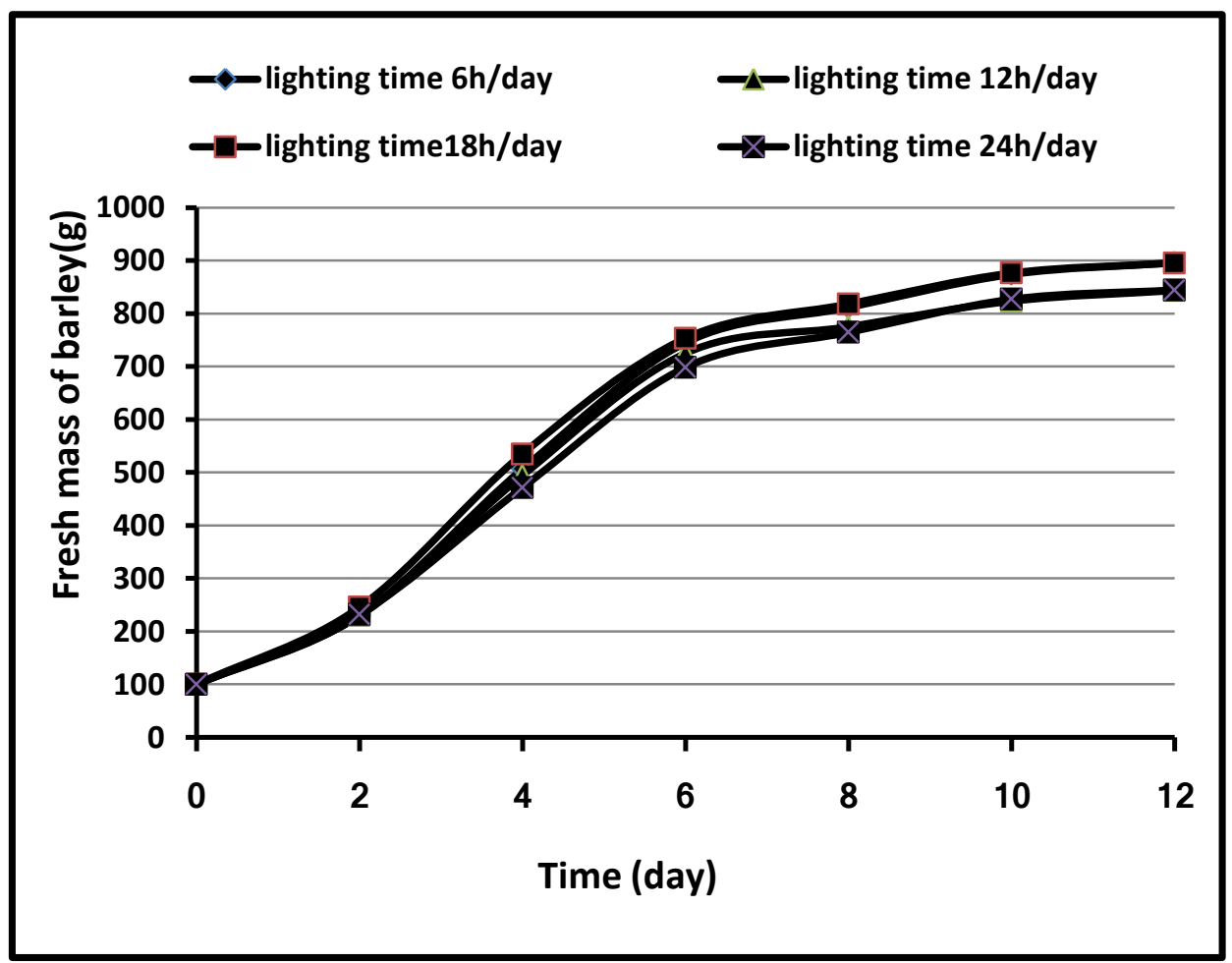

Fig.(8): Time of barley growth and fresh mass.

Generally, under the four lighting times tested, the relation between time and fresh mass is an increasing from 1:10 day. However, the mass increase diminish after six days.

Under lighting time 6h/day, the barley appeared yellow(weak) and the root mat was so thick. The lowest fresh mass was obtained with lighting time of 24h/day, where the barley appeared weak. The two carves for 12 and $18 \mathrm{~h} /$ day gave an intact fresh mass with two close.

The fresh mass obtained with lighting time of $12 \mathrm{~h}$ /day coincides with that obtaind by; El-Deeba et al. 2009. It can be concluded that; amongst the four tested lighting times, $12 \mathrm{~h} /$ day is chosen for energy saving. 
4- Effect of the air changes per hour on growth of barley:

Figure (9) shows the relationships between time of the barley growth and fresh weight under the four air changes tested: (30,40,50and 60 times per hour).

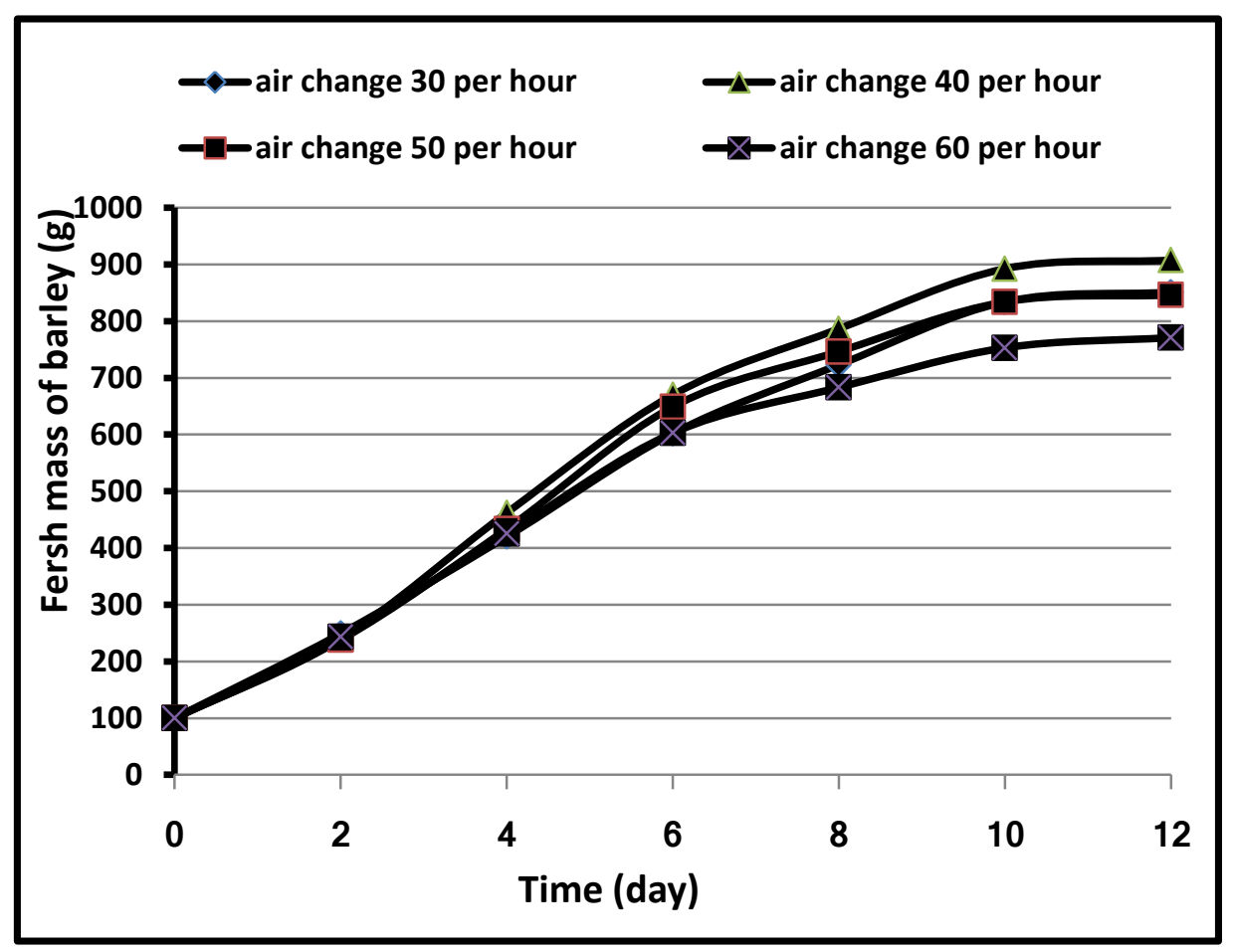

Fig.(9):Time of barley growth and fresh mass.

There was a slight difference in fresh weight between air change rate of 50 and 30 time per hour. The lowest fresh weight obtained with air changes 60 time per hour and the highest fresh mass was obtained with air change rate of 40 times per hour.

\section{SUMMARY}

This study aims to investigate slope parameter and environmental parameters affecting the "NFT" by using a small unit and a semienvironmental control - chamber.

The studied parameters are: 
The slope of the NS channel . Four slopes were tested: 5,10, 20 and 25\% Environmental parameters :

- Concentration of the NS are : $0.5,1,1.5 \%$ were tested in addition to tap water as control.

- Lighting type: three types of lighting were tested: light- emitting diodes $\left(\mathrm{LED}_{\mathrm{S}}\right)$, fluorescent lamps ,compact fluorescent lamps $\left(\mathrm{CFL}_{\mathrm{S}}\right)$ in addition a natural light as control.

- Lighting time : four lighting times were tested: 6,12,18 and 24 $\mathrm{h} /$ day.

- Air change per hour: four air changes rates were tested: 30, 40, 50 and 60 times per hour.

\section{CONCLUSIONS}

Under the tested slope range (5-25\%), the slope of 5\% under feed pump discharge of $4.66 \mathrm{~L} / \mathrm{min}$ is optimal for the production of the green fodder. This slope corresponds to depth of NS and speed before transplanting of $3 \mathrm{~mm}$ and $0.1 \mathrm{~m} / \mathrm{s}$ respect to, Mosallam et al., 2015.

Under the tested concentrations of the nutrient solution, the concentration of $1 \%$ is optimal for the production of barley green - fodder.

When studying the effect of lighting type on the plant growth, the results showed that there is a slight difference between the results for the four lighting types tested. So, it is preferable to produce the green fodder under light-emitting diodes $\left(\mathrm{LED}_{\mathrm{S}}\right)$ to save the energy consumption.

The results showed that the lighting time of $12 \mathrm{~h} /$ day is optimal for the production of green fodder to save the energy consumed in lighting.

Under lighting time 6h/day, the barley appeared yellow(weak) and the root mat became so thick. Under lighting time of 24/day the barley appeared yellow.

When studying the effect of air change rates on the plant growth ,the results showed that the 40 times per hour is optimal for the production of green fodder. 


\section{REFERANCES}

Aldrich R. A., and J. W. Bartok (1994). Greenhouse engineering. 3rd rev., NRAES (USA). Greenhouse series. no. 33.

Al-Karaki G. N., and N. Al-Momani (2012). Evaluation of some barley cultivars for green fodder production and water use efficiency under hydroponic conditions. Jordan Journal of Agricultural Sciences, $7(3): 448-454$.

Ashour N. I., M. S. Serag, A. A. El-Haleem and B. B. Mekki (1997). Forage production from three grass species under saline irrigation in Egypt. Journal of arid environments, 37(2):299-307.

Bourget M.C. (2008). An introduction to light emitting diodes. Hortscience ,43:1944-1946.

Carly M. (2011). Leafy asian vegetables and their nutrition in hydroponics. Industry \& Investment NSW., ISBN 978174256 0779,(24):7-8.

Cooper A.(1996). The ABC of NFT. 2ed. Grower Books, London, UK,: 20.

El-Behairy U. A. A. (1994). The effect of levels of phosphorus and zinc in the nutrient solution on macro and micro nutrients uptake and translocation in cucumber ('Cucumis Sativus' L.) grown in nutrient film technique (NFT) (Doctoral dissertation, University of London ,56.

El-Deeba M. M. , M. N. El-Awady, M. M. Hegazi , F. A. Abdel-Azeem and M. M. El-Bourdiny (2009). Engineering factors affecting hydroponics grass- fodder production. The 16th. Annual Conference of the Misr Society of Ag. Eng., 25 July: 1647-1666.

Folta K., L. Koss , R. M. Morrow , H. Kim , J.D. Kenitz, R.Wheeler and J. Sager ( 2005). Design and fabrication of adjustable red- 
green-blue LED light arrays for plant research. BMC Plant Bioi., 5: 17.

Gordon A.(2008). Home hydroponics, http://www.geocities.com./cache/hydroponics.html:1-7

Graves C.J. (1983). The nutrient film technique. Horticutural Review. 5: $1-44$.

Graves C.J. and R.G. Hurd (1983) .intermittent solution circulation in the nutrient film technique Acta hortic.,133:47-52.

Ikeda and Hideo (2011). Plant factory trans action son sensor sound micro machines, 131(6):200-205.

Jane B. and A. Neil (2011). Campbell. Biology: 9th Edition. California: Pearson Education.

Jenner G. and N. Starkey(1980). Nutrient film technique: Practicalities of cadmium. Plant Soil, 49: 333-342.

Liguo T. , M. Qinghao, W. Liping and D. Jianghui(2014). A Study on crop growth environment control system. International Journal of Control and Automation ,7(9):357-374.

Lynette M.(1999).Nutrient Film Technique (NFT) Production of Lettuce. Source. Available from: URL [http:www.cropking.com/NFT lettuce 1 .shtm1],:1-3.

Maher M. J. (1977). The use of hydroponics for the production of greenhouse tomatoes in Ireland. In $4^{\text {th }}$ International Congress on Soilless Culture, Las Palmas (Spain),:161-169.

Massantini F. and G. Magnani (1980). Hydroponic fodder [cereals] growing: use of cleaner-separated seed. In $5^{\text {th }}$. soilless culture. Wageningen (Netherlands). 
Mosallam M.A., M. E. Shetawy, R. R. EL-Bessoumy and T. A. Fattah (2015). Empericl graphs relating the main factors affecting a nutrient-film system. Misr Soc.of Ag.Eng.,32(4):1709-1716.

Resh H. M.(1991). Hydroponic food production. Woodbridge Prespup. California,: 462.

Spensley K., G. W. Winsor and A. J. Cooper (1978). Nutrient film technique-crop culture in flowing nutrient solution [Tomatoes], (No. 79-415860. CIMMYT.),9:299:305.

Stout B. A. (1984). Energy use and management in agriculture. belmont, CA: Breton Publishers.

\section{الملخص العربحى}

عFT عوامل التحكم البيئية المؤثرة على إنتاج العلف الأخضر بتقانة الغثاء المغذى محمود أحمد مسلم(')، محمد السيد شتيوى(")، رزق ربيع البسومى(") و طه عبد الفتاح محمد(؛) يهذف هذا البحث الى دراسة عامل تصميمى و عو امل بيئية للزر اعة بنظام الغشاء المغذى وذاء

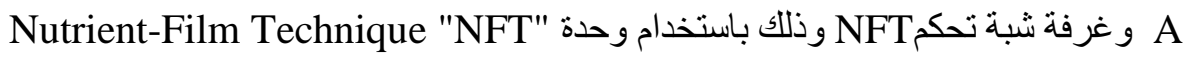
semi- environmental Control Chamber.

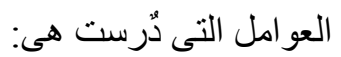
بوي: بيل قناة سريان المحلول المغذى وقد تمت دراسة اربعة ميول هى : 0،

$$
\begin{aligned}
& \text { \% \% r r r ، . . } \\
& \text { العو امل البيئية: }
\end{aligned}
$$$$
\text { ـ تركيز المحلول المغذى: 0, •، ؛,0, 1\% وماء الصنبور. }
$$$$
\text { - نوع الاضاءة : ضو طبيعى، مصابيح فلورسنت • سم سم ، }
$$$$
\text { LEDS. }
$$

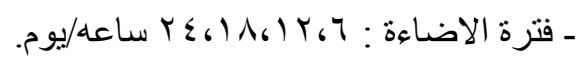

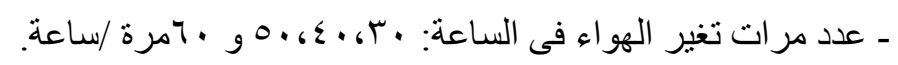

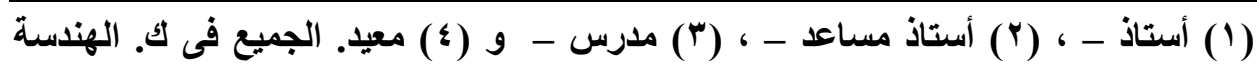
الزراعية ، ج. الأزهر 


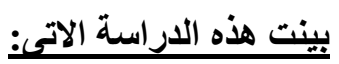

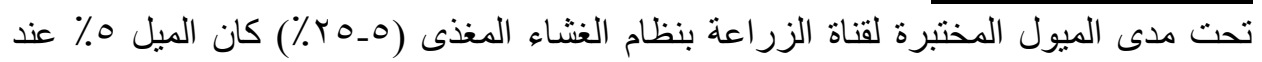

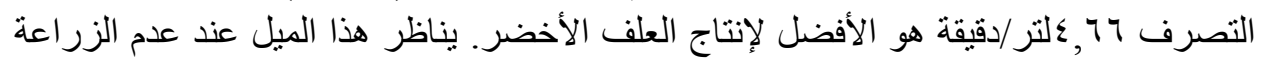

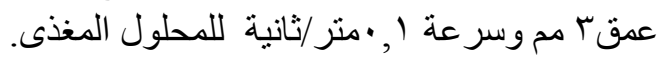

تحت مدى تركيزات المحلول المغذى المختبرة كان التركيز ٪ هو الأفضل لإنتاج علف أخضر من نبات الثعبر.

أظهرت النتائج انه ليس هناك فروق جوهرية بين أنواع الاضاءة الأربعة المستخدمة على انتاج

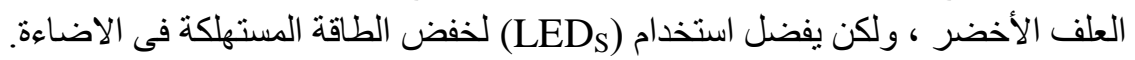

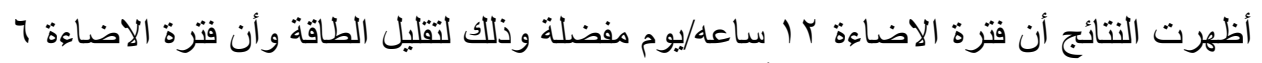

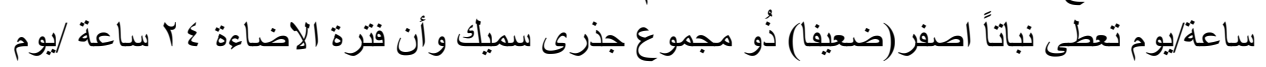

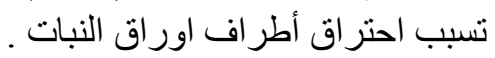

عند دراسة اثر عدد مرات تغير الهواء ، أظهرت النتائج ان تغير الهواء ·ــ مرة /ساعة يعطى أفضل انتاج للعلف الأخضر. 